JUN-QIANG LENG, Ph.D.

E-mail: lengjunq@tom.com

Harbin Institute of Technology

${ }^{1}$ School of Management, Harbin, P. R. China

${ }^{2}$ School of Automobile Engineering, Weihai, P. R. China

YU-QIN FENG

Heilongjiang Institute of Technology

School of Automobile Engineering, Harbin, P. R. China

YA-PING ZHANG

YI HE

Harbin Institute of Technology

School of Automobile Engineering, Weihai, P. R. China
Traffic in the Cities

Preliminary Communication

Accepted: Jan. 10, 2012

Approved: Oct. 3, 2012

\title{
DEVELOPMENT AND USAGE OF TRAVEL TIME RELIABILITY MODEL FOR URBAN ROAD NETWORK UNDER ICE AND SNOWFALL CONDITIONS
}

\begin{abstract}
This paper discusses the travel time reliability of road network under ice and snowfall conditions. With the introduction of correction function for the influence of ice and snowfall conditions on free travel time and capacity, the function of travel time was established. According to the limitation of the current travel time reliability, the new definition was defined on the basis of quantifying the relationship between LOS (Level of Service) and travel time reliability. The breakthrough of the traditional idea that the route travel time reliability model was set by general series system was made by considering the route as a whole unit; instead of using a paralleling system; another breakthrough was made to calculate the weighted average travel time reliability of $O D$ (Original Destination) pair. On the basis of $O D$ pair travel time reliability, the road network reliability model was set up. A partial road network was taken as an example to validate the effectiveness and practicality of the evaluation methodology.
\end{abstract}

\section{KEY WORDS}

travel time reliability, Ice and Snowfall Based-BPR, Level of Service, Original Destination pair

\section{INTRODUCTION}

Compared with the connection reliability, the study on travel time reliability started later. Asakura et al. [1] suggested reflecting the road network reliability with the volatility of travel time, i.e. the concept of travel time reliability. It was defined as the ratio between the practical travel time and the free travel time between the given OD pair. In this concept, the free travel time is considered as the comparison standard. Asakura [2] studied the travel time reliability under the degraded capacity (due to the damaged road segment), and defined the travel time reliability as the travel time ratio between the degraded capacity and the normal one, which was used to measure the state of road network. Apparently, the closer the ratio approaches 1 , the better the traffic state of the road network. Otherwise, it is worse and it may even happen that the destination may not be reached. Lida [3] defined the travel time reliability as the probability of reaching the destination within the limited time, which initially studied the network reliability with the theory of probability. Lam and Xu [4m 5] adopted TFS (Traffic Flow Simulator) to evaluate the travel time variance and covariance caused by the alteration of the traffic demand. Based on the above study Chen et al. [6] made a research and illustrated that the evaluation result of travel time reliability is (was) different with different path choice models. Lomax et al. [7] suggested describing travel time reliability with Buffer Index, which was defined as the ratio between the additional time the traveller needs to arrive at the destination on time and the average travel time. Similarly, Chen et al. [8] referred to the concept of Buffer Time, which was used to measure the ability to handle uncertain factors of the road network and was useful for the decision under uncertain condition. Haitham Al-Deek et al. [9] defined the travel time reliability as the probability that the practical travel time was less than or equal 
to the total time of the free flow travel time and the additional time (that the public could accept under certain requirement of LOS). Based on the method of possibility, H. Tu et al. [10] analyzed the travel time reliability to evaluate the operating quality of highway, soon afterwards, used the cell transmission model to study travel time reliability of the road network [11]. Lam et al. $[12,13]$ studied the network reliability on rainy days. Higatani Akito et al. [14] used the field observation data to study the travel time reliability of Hanshin highway network. Sohn Keemin et al. [15] proposed the method of evaluating the dynamic travel time, which set the basis for the calculation of the travel time reliability.

In summary, on the one hand, the current study is aimed mostly at the daily traffic jams and considers less the natural disasters and adverse weather conditions (earthquake, typhoon, snowfall, etc). Currently, the cities are facing high-incidence season of disasters. For example, Shenyang, Beijing in China and other big states in the USA such as California, Oregon, Washington State, very often have traffic gridlocks. On the other hand, the road network is formed by connecting a road segment and intersection through different ways. At present, most studies apply the theory of series or parallel system. The travel time reliability of a path is calculated by the series unit and OD pair travel time reliability is explained by a parallel path. Additionally, the travel time reliability of road network is figured out by the weighted average or minimum of OD pairs. With the method above, for instance, there is a path with 10 components and the reliability of each component is 0.5 . Referring to the concept of reliability, the reliability of this path is 0.5 as well. However, if considering it in accordance with the general series multiplying principle, the reliability of this path will convert to 0 . So, an example can be deduced from this. If an OD pair has 10 paths and the reliability of each path is 0.1 , then in the light of parallel multiplying principle, the reliability can be calculated as 0.65 . In fact, the reliability when travellers may choose any path is 0.1 . Consequently, the evaluation of travel time reliability of a path will be lower than the practical one, while the evaluation of OD pair will be higher than the practical value, which is distinct from the practical situation.

Accordingly, this paper aims to study the travel time reliability of urban road network under ice and snowfall conditions, which provides theoretical support for improving the road network planning, disaster relief and prevention, as well as traffic management.

This paper is organized as follows. The following section establishes the models of road segment travel time and delay at intersection under ice and snowfall conditions. Then, Section 3 builds up the modes of travel time reliability for road segments and intersection. In Section 4, the road network travel time reli- ability is established. Section 5 provides a numerical example on a small-size network to demonstrate the applications of the proposed model. The final section then concludes the paper and recommends the followup.

\section{TRAVEL TIME MODELS OF ROAD NETWORK UNITS}

\subsection{Travel time of road segment}

The Bureau of Public Road (BPR) function is widely used in road segment travel time calculation. Under ice and snowfall conditions, the visibility and friction factor decline significantly, and the traffic property and driver's behaviour are distinct from that of the normal state. Therefore, the BPR function based on the normal weather condition could not be applied efficiently under ice and snowfall conditions. With the introduction of correction function for the influence of ice and snowfall conditions on free travel time and capacity, the Ice and Snowfall Based-BPR (ISB-BPR) function is used to describe the road segment travel time. It can be written as:

$$
T_{a}(I)=g_{t}(I) t_{a}\left[1+\beta\left(x_{a} /\left(g_{c}(I) C_{a}\right)\right)^{n}\right]
$$

Where $I$ is the intensity of ice and snowfall; $T_{a}(I)$ is travel time of road segment under ice and snowfall conditions, $s ; t_{a}$ is free travel time on link $a, s ; g_{t}(I)$ is correction function of free travel time under ice and snowfall conditions; $g_{c}(I)$ is correction function of capacity under ice and snowfall conditions; $x_{a}$ is traffic volume on road segment $a, p c u / h ; C_{a}$ is capacity of road segment $a, \mathrm{pcu} / \mathrm{h} ; \beta, \mathrm{n}$ is parameters which need to be calibrated.

$g_{t}(I)$ and $g_{c}(I)$ are related to the intensity of ice and snowfall, the form of the two parameters may be written as $g_{c}(I)=a_{2} e^{b_{2} l}$ and $g_{c}(I)=a_{2} e^{b_{2} l}$, respectively. Where $a_{1}, b_{1}$ and $a_{2}$ are positive, and $b_{2}$ is negative [16]. Accordingly, they are satisfied with the following conditions: when $g_{t}(0)=1$, $g_{c}(0)=1$, ISB-BPR function is equal to BPR function. $g_{t}(I)$ is a monotonically increasing function, and $g_{t}(I) \geq 1 . g_{c}(I)$ is a monotonically decreasing function and $0<g_{c}(I) \leq 1$. In practical application, $g_{t}(I)$ and $g_{c}(I)$ need to be demarcated according to the field observation data.

With the observation data under normal weather conditions in different road segments of Harbin city, the BPR function is demarcated. $\beta=1.13, n=4$ for express way and $\beta=1.4, n=3$ for other road segments. The observation data of free travel time and capacity of the different road segments are showed in Table 1 and Table 2, respectively, and the value of $g_{t}(I)$ and $g_{c}(I)$ can be found in Table 3 and Table 4, respectively. 
J. Leng et al.: Development and Usage of Travel Time Reliability Model for Urban Road Network under Ice and Snowfall Conditions

Table 1 - Free travel time of per distance segment link under different conditions (s/km)

\begin{tabular}{|c|c|c|c|c|}
\hline Conditions & Gongbin Rd & Changjiang Rd & Huanghe Rd & Wenhua Rd \\
\hline Normal & 43.8 & 59.1 & 66.2 & 66.7 \\
\hline Little snow & 51.6 & 67.9 & 73.6 & 71.7 \\
\hline Moderate snow & 60.0 & 78.8 & 83.8 & 78.5 \\
\hline Heavy snow & 65.1 & 90.3 & 93 & 88.9 \\
\hline Blizzard & - & - & - & 102.6 \\
\hline Slush & - & - & - & 85.3 \\
\hline Glare ice & - & - & - & 109.8 \\
\hline Consolidated snow & - & - & - & 146.5 \\
\hline
\end{tabular}

Table 2 - Segment capacity under different conditions (pcu/h)

\begin{tabular}{|c|c|c|c|c|}
\hline Conditions & Gongbin Rd & Changjiang Rd & Huanghe Rd & Wenhua Rd \\
\hline Normal & 4,810 & 3,363 & 3,106 & 3,840 \\
\hline Little snow & 4,280 & 3,044 & 2,834 & 3,533 \\
\hline Moderate snow & 3,992 & 2,869 & 2,712 & 3,379 \\
\hline Heavy snow & 3,350 & 2,463 & 2,464 & 3,149 \\
\hline Blizzard & - & - & - & 2,381 \\
\hline Slush & - & - & - & 3,203 \\
\hline Glare ice & - & - & - & 1,516 \\
\hline Consolidated snow & - & - & - & 1,289 \\
\hline
\end{tabular}

Table 3 - Value of $g_{t}(l)$ under different conditions

\begin{tabular}{|c|c|c|c|c|}
\hline Conditions & Gongbin Rd & Changjiang Rd & Huanghe Rd & Wenhua Rd \\
\hline Normal & 1.00 & 1.00 & 1.00 & 1.00 \\
\hline Little snow & 1.18 & 1.15 & 1.11 & 1.08 \\
\hline Moderate snow & 1.37 & 1.33 & 1.27 & 1.18 \\
\hline Heavy snow & 1.49 & 1.53 & 1.4 & 1.33 \\
\hline Blizzard & - & - & - & 1.54 \\
\hline Slush & - & - & - & 1.28 \\
\hline Glare ice & - & - & - & 1.65 \\
\hline Consolidated snow & - & - & - & 2.20 \\
\hline
\end{tabular}

Table 4 - Value of $g_{c}(I)$ under different conditions

\begin{tabular}{|c|c|c|c|c|}
\hline Conditions & Gongbin Rd & Changjiang Rd & Huanghe Rd & Wenhua Rd \\
\hline Normal & 1.00 & 1.00 & 1.00 & 1.00 \\
\hline Little snow & 0.92 & 0.93 & 0.95 & 0.95 \\
\hline Moderate snow & 0.81 & 0.85 & 0.87 & 0.88 \\
\hline Heavy snow & 0.70 & 0.73 & 0.79 & 0.79 \\
\hline Blizzard & - & - & - & 0.62 \\
\hline Slush & - & - & - & 0.83 \\
\hline Glare ice & - & - & - & 0.40 \\
\hline Consolidated snow & - & - & - & 0.31 \\
\hline
\end{tabular}




\subsection{Delay at intersection}

Because of small spatial range of intersection, the travel time depends mainly on delay. The delay may be chosen to measure the travel time reliability. Delay correlates with various factors including the form of the intersection, the signal control and capacity, etc. Also, ice and snowfall conditions have great impact on the capacity. From the delay model in HCM2000, the parameter which is influenced by ice and snowfall conditions is the lane group capacity, and the equation can be written as:

$$
C A P_{i}=S_{i} \cdot(g / c)_{i} \cdot f_{a d} \cdot f_{p}
$$

Where $C A P_{i}$ is the capacity of lane group $i ; S_{i}$ is the saturation flow rate of lane group $i$, and it is related to ice and snowfall conditions; $(g / c)_{i}$ is the split of lane group $l ; f_{a d}$ is the impact of the accelerationdeceleration on capacity, and it is related to ice and snowfall conditions. The recommended value is 0.88-0.94 in the normal state and 0.71-0.92 under ice and snowfall conditions; $f_{p}$ is the impact of pedestrians and non-motorized vehicles on the capacity of right-turning vehicles.

\section{TRAVEL TIME RELIABILITY OF ROAD NETWORK UNIT}

\subsection{Travel time reliability of road segment}

\subsubsection{Definition}

At present, the definition of travel time reliability could be classified into two groups. The first group defines the free travel time or the average travel time as the expected one needed by the traveller. The acceptable travel time threshold value for the traveller was provided as the standard of measuring the validity of the road, which was used to define the travel time reliability. This concept points out the correlation of the travel time reliability with LOS requirement, and in the formula, the threshold value reflects different requirement for LOS. The LOS requirement is a requirement for traffic service level presented by the travellers. For the same road traffic condition, the higher the LOS required by the travellers, the lower the reliability of the relevant travel time. On the contrary, the reliability of the travel time becomes higher. However, the relationship between LOS and the threshold value is not clarified and there are no specific threshold values for different LOS requirements. The thresholds are provided factitiously as $5 \%, 10 \%, 15 \%, 20 \%$ etc, and therefore the evaluation results are not relevant with the requirements for the LOS. The second group definition is expressed in the change rate of the travel time and figures out the probability of this change rate satisfying certain range. The second concept has a similar limitation with the first one, since the relationship between the travel time change ratio and the requirement for LOS is not explicit, which leads to the non-corresponding relationship between the LOS requirement and the evaluation results.

Accordingly, the travel time reliability of the road segment can be defined as the probability that the travel time the traveller spends on the road is less than or equal to the expected travel time on a special road and conditions. The definition formula is as follows

$R\left(\bar{T}_{i}\right)=P\left(\bar{T}_{i} \leq E\left[T_{L O S}\right]\right)$

Where $\bar{T}_{i}$ is the travel time per unit distance of road segment $i, \mathrm{~s} / \mathrm{km}$; $E\left[T_{\text {Los }}\right]$ is the upper limit of the expected travel time per unit distance, $\mathrm{s} / \mathrm{km}$.

The travel time function of the road segment under ice and snowfall conditions is normalized and the travel time per unit distance can be figured out, and then substituted into equation (3).

$R\left(\bar{T}_{i}\right)=P\left(g_{t}(I) \overline{t_{\alpha}}\left[1+\beta\left(x_{a} /\left(g_{c}(I) C_{a}\right)\right)^{n}\right] \leq E\left[T_{\text {LOS }}\right]\right)$

Where $\overline{t_{\alpha}}$ is the free travel time per unit distance under normal weather; other parameters have the same meanings as above.

From the definition formula, it can be seen that the concept of the travel time reliability relates closely with LOS requirement. The concept firstly defines the classification of the road segment and there are different LOS standards for different road segments, which require different $E\left[T_{L O S}\right]$; under the same classification of road segment, the expected travel time $E\left[T_{L O S}\right]$ is different for the different LOS requirement. Therefore, there would be different evaluation results, the higher the LOS requirement, the lower the value of $E\left[T_{L O S}\right]$ with lower reliability. Otherwise, the reliability will be higher due to lower LOS requirement.

\subsection{2 $E\left[T_{L O S}\right]$ Determination}

Saturation is used as the standard for LOS classification, and it is necessary to obtain the standard with the travel time of the unit distance. The BPR function constructs the relationship between saturation and travel time. Therefore, it is possible to use the BPR function to shift the standard of saturation into travel time per unit distance. Thus, the floating car was used in making an inquiry into the free travel time of different rank roads of Harbin, and the travel time per unit distance of various road segments at different LOS requirements was calculated with the calibrated BPR function for express, $\beta=1.13, n=4$; for other road segment, $\beta=1.4, n=3$. The results are shown in Table 5.

\subsection{Travel time reliability of intersection}

The travel time reliability of intersection is studied with the units of lane group; it is defined as the probability that the traffic in a certain lane group passes 
Table 5 - $E\left[T_{\text {Los }}\right]$ of urban street in Harbin $(\mathrm{s} / \mathrm{km})$

\begin{tabular}{|c|c|c|c|c||}
\hline LOS & Expressway & Main Road & Secondary Road & Branch Road \\
\hline \hline 1 & $<50.2$ & $<79.6$ & $<96.4$ & $<134.0$ \\
\hline 2 & $50.2-64.1$ & $79.6-104.9$ & $96.4-127.1$ & $134.0-176.7$ \\
\hline 3 & $64.1-93.3$ & $104.9-146.6$ & $127.1-177.6$ & $176.7-247.0$ \\
\hline 4 & $>93.3$ & $>146.6$ & $>177.6$ & $>247.0$ \\
\hline
\end{tabular}

through the intersection within a special time slot smoothly under the given conditions and LOS requirements. Most of the studies pointed out the relationship between the intersection reliability and LOS requirement, but no specific analytic relations were shown in the definition. According to the particularity of research conditions in this paper, the conception was defined as follows: 1 ) the special time slot: the peak hours; 2) the given conditions: namely, both the internal and the external conditions of the intersection, the former including traffic facilities, geometry, and signalized control conditions, and the latter including ice and snowfall conditions; 3) specified LOS: different LOS required at different intersections. For example, LOS in the CBD is relatively lower than that of the suburbs. The difference of LOS requirements results in different reliability. And it is apparent that the higher the LOS requirement, the lower the reliability, and vice versa. The travel time reliability of a lane at intersection is defined as follows:

$R_{i k}=P\left[D_{i k} \leq \delta D_{\text {LOS }}\right]$

Where $R_{i k}$ is the travel time reliability of lane $k$ at intersection $i ; D_{i k}$ is the delay of lane $k$ at intersection $i$; $D_{\text {LOS }}$ is the upper limit of delay that corresponds with specific LOS requirement. DLOS represents different LOS requirements. It is apparent that the smaller the value, the higher the requirements for LOS, and the lower the reliability, and vice versa. $\delta$ is the traveller's toleration coefficient of delay for different intersections. The specific value is illustrated in HCM2000.

\section{ESTABLISHMENT OF ROAD NETWORK TRAVEL TIME RELIABILITY MODEL}

The basic units of road network are road segments and intersection. The road segment and intersection make up a path, and one or more paths make up the OD pair, while many OD pairs make up the road network. According to different research scopes, the travel time reliability can be classified into the reliability of road network unit (road segment and intersection), path as well as OD pair and road network.

\subsection{Model of path travel time reliability}

The path travel time reliability means the probability of completing the travelling on the designated path in special time, condition and LOS requirement. It closely relates to the traffic operation state of all road segments and intersections that compose the path. Currently, most of the studies consider that the path is formed by road segments and intersections in the way of series connection. Therefore, path reliability depends on the reliability of the component road segments and intersections. There are two different ideas to handle this situation; for one thing, the reliability of the path is decided by the unit that has the lowest reliability. The formula goes as follows

$R_{k}=\min \left\{\delta_{a, k}^{s t} R_{a}, \delta_{n, k}^{s t} R_{n}\right\}, a \in A, n \in N, \forall k \in K_{s t}$

Where $R_{k}$ is the travel time reliability of path $k ; R_{a}$ is the travel time reliability of road segment $a ; R_{n}$ is the travel time reliability of lane group at intersection $n$; $A$ is the set of road segments of the $k$-th path that composes the OD pair st; $N$ is the set of intersections of the $k$-th path that composes the OD pair st; $\delta_{a, k}^{s t}$ is 0-1 variable, if road segment a lies in the $k$-th path of the OD pair st; then $\delta_{a, k}^{s t}=1$, or $\delta_{a, k}^{s t}=0 ; \delta_{n, k}^{s t}$ is $0-1$ variable, if lane group of intersection $n$ lies in the $k$-th path of the OD pair st, then $\delta_{n, k}^{s t}=1$, or $\delta_{n, k}^{s t}=0 ; K_{s t}$ is the path set between the OD pair st.

For the other, the path reliability is calculated with the reliability of road segments and intersections. The formula is as follows,

$R_{k}=\prod_{a} \delta_{a, k}^{s t} R_{a} \prod_{n} \delta_{n, k}^{s t} R_{n}=\prod_{a \in A} R_{a} \prod_{n \in N} R_{n}, \forall k \in K_{s t}$

To analyze the irrationality of the two ideas mentioned above, the simple path in Figure 1 was taken as an example, in which 4 joints and 3 road segments are included. The joints 1 and 4 are the origin and destination points, respectively, while joints 2 and 3 are intersections. The data at the bottom area of the Figure is the practical travel time distribution and expected value on the road segment, while the data at the top area of the Figure is the delay distribution and expected value at the intersection. By Matlab 7.0 simulation, the travel time reliability of joints 2 and 3 are 0.3513 and 0.3490 , respectively, and the travel time reliability of the road segments are 0.2449, 0.7689, and 0.7725, respectively. According to the first idea, the reliability of the path is 0.2449 , and that of the second idea is 0.0178 . The above computing ideas do not conform to the concept of the path travel time reliability. The concept focuses or stresses the overall travel time and reliability from the origin to the destination, instead 
of emphasizing the travel time and reliability of every composing unit. The two computing ideas mentioned above, however, care for the travel time and reliability of every composing unit in the path. For example, if the travel time reliability of a certain unit is 0 , the reliability of the path will be 0 even though the other unit reliability is 1 . However, from the prospective of the concept, it is apparent that the travel time reliability of this path is not 0 .

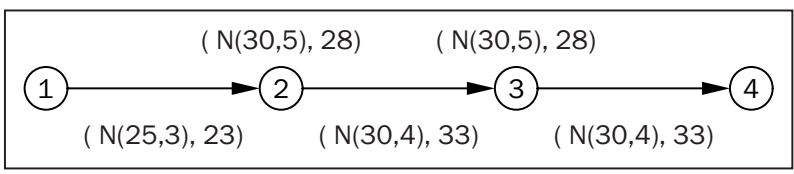

Figure 1 - Schematic diagram of path travel time reliability

By breaking the traditional series connection theory to analyze the travel time reliability of the path, it was defined as follows: the path travel time reliability is the probability that the expected travel time does not exceed the practical travel time on special time, condition and LOS requirement. The expression in the formula is:

$R_{k}=P\left(\sum_{a \in A} \delta_{a, k}^{s t} T_{a}+\sum_{n \in N} \delta_{n, k}^{s t} T_{n} \leq E\left[T_{k q}\right]\right)$

Where $T_{n}$ is the travel time at intersection $n ; T_{a}$ is the travel time on link $a ; E\left[T_{k q}\right]$ is the expected travel time for path $k$,

$$
E\left[T_{k q}\right]=\sum_{a \in A} \delta_{a, k}^{s t} E\left[T_{a L O S}\right]+\sum_{n \in N} \delta_{n, k}^{s t}\left(t_{n}+E\left[D_{n L O S}\right]\right) ;
$$

$E\left[T_{a L O S}\right]$ is the expected travel time for road segment $a ; t_{n}$ is the travel time at intersection $n$ area under the assumption that there is no intersection or conflict; $E\left[D_{n L O S}\right]$ is the upper limit of delay under the expected LOS at intersection $n$.

According to the formula above, the travel time reliability of the path shown in Figure 1 is 0.4960 , which is significantly greater than the results of formula (6) and formula (7) between the largest and the smallest value of the composing units reliability.

\subsection{Model of OD pair travel time reliability}

The OD pair travel time reliability is a comprehensive evaluation index for all paths travel time between the given OD pairs. It is the probability that the travellers go form point $\mathrm{O}$ to point $\mathrm{D}$ with special LOS requirement under special time slots and conditions. Currently, the research ideas for OD pair travel time reliability tend to lean to one side, most of which incline to the method of parallel connection theory. There are many paths between OD pair. $R_{k}$ is travel time reliability of path $k$. Suppose there are $m$ paths, and the OD pair reliability can be demonstrated as follows:

$R_{s t}=1-\prod_{k=1}^{m}\left(1-R_{k}\right)$ where $R_{s t}$ is travel time reliability of OD pair st.

To analyze the irrationality of the two research ideas mentioned above, the simple OD pair in Figure 2 was taken as an example. Suppose that there are 10 paths between the OD pair in this Figure, and the travel time reliability of each path is 0.1 . According to the paralleled idea mentioned above, the travel time reliability of the OD pair is 0.65 . That is to say, the probability of the traveller arriving at the destination within the expected time is 0.65 . However, it is impossible. The fact is that for any one of the 10 paths chosen by any of the travellers, the travel time reliability will never be more than 0.1. If we add up the quantity of the path to 30 , the travel time reliability will be 0.958 , and with more paths added, the travel time reliability will be approaching 1 . It is obvious that this outcome will never be actualized.

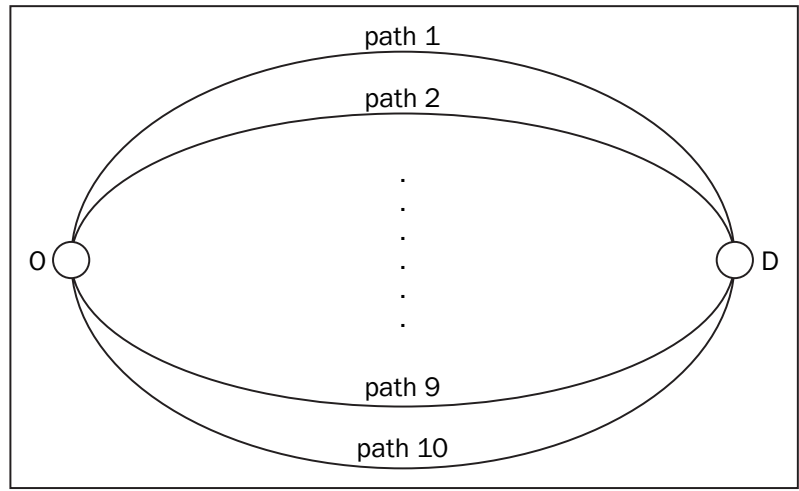

Figure 2 - Schematic diagram of $O D$ pair travel time reliability

Accordingly, this paper breaks through the traditional paralleled connection theory and defines the OD pair travel time reliability as the weighted average value of the travel time reliability of all paths between the OD pair. The weight of a path is the ratio of the traffic volume of this path to the overall traffic volume of OD pair. The travel time reliability of OD pair can be computed by the following formula

$R_{s t}=\sum_{k=1}^{K} R_{k} \cdot q_{k} / \sum_{k=1}^{K} q_{k}$

Where $K$ is the number of the paths between OD pair st; $q_{k}$ is the traffic volume of path $k$.

\subsection{Model of road network travel time reliability}

This paper defines the travel time reliability of road network as the probability that a trip between the OD pairs in a given road network can be made successfully within a specified interval of time under the required LOS and conditions. The concept was defined as follows: 1) it is closely related to traffic operation state of all OD pairs; 2) the special time slots are the rush hours; 3 ) the required conditions in this paper are different ice and snowfall conditions; 4) different 
requirements for LOS will lead to different travel time reliability.

At present, most of the studies consider that the travel time reliability of road network depends on the reliability of OD pairs. To summarize, there are three different ideas. And the models are:

$$
\begin{aligned}
& R_{\min }=\min \left\{R_{s t}\right\} \\
& R_{\text {avg }}=(1 / s) \sum_{s=1}^{s} R_{s t} \\
& R_{\text {wgt }}=\sum_{s=1}^{s} R_{s t} \cdot q_{s t} / \sum_{s=1}^{s} q_{s t}
\end{aligned}
$$

where $S$ is the number of OD pairs in the road network; $q_{s t}$ is the traffic volume of OD pair st.

The models mentioned above aim to figure out the minimum, mathematical average and the weighted mean value of the travel time reliability of OD pairs in the road network. Formula (11) takes the minimum of the travel time reliability in the road network as the reliability of the overall road network, which obviously takes a part of the whole, and it will make the evaluation result smaller than the actual value. Formula (12) takes the arithmetic mean of OD pairs travel time reliability as the reliability of the overall road network. This method treats all the OD pairs equally in terms of their importance upon the road network, which will inevitably zoom in the effect of minor OD pairs to the whole network and lead to larger deviation of the evaluation result to the actual value. Formula (13) is the weighted average of OD pairs travel time reliability, and the weight of each OD pair depends on the proportion of the OD volume on the overall network OD volume.

Accordingly, the model of travel time reliability of road network may be constructed by referring to the research idea of formula (13). It is formulated as:

$R_{n}=\sum_{s=1}^{s} \sum_{k=1}^{K} R_{s k}\left(q_{s k} / \sum_{k=1}^{K} q_{s k}\right) \cdot\left(q_{s} / \sum_{s=1}^{s} q_{s}\right)$

where $R_{n}$ is the travel time reliability of road network; $R_{s k}$ is the travel time reliability of the $K$-th path of the sth OD pair in the road network; $q_{s k}$ is the traffic volume of the $K$-th path of the s-th OD pair in the road network; $S$ is the number of OD pairs. $K$ is the number of paths in the OD pair $s$.

\section{APPLICATION}

To examine the applicability of the analytical method for the travel time reliability of road network, a partial road network in Harbin was selected as an example. The periods to be analyzed are rush hours in the morning under different ice and snowfall conditions. The simplified road network is shown in Figure 3, which includes 20 joints and 56 directed arcs.

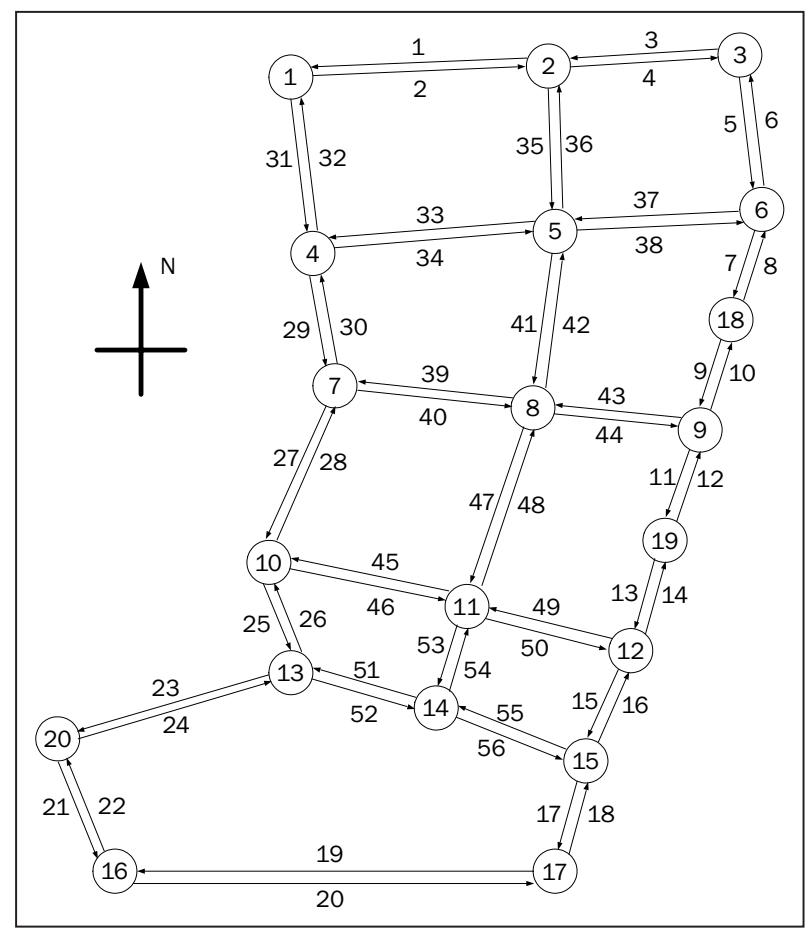

Figure 3 - Simplified study partial road network in Harbin

According to formula (8), the travel time reliability of every path in each OD pair is calculated respectively. Due to limited space, only part of the simulation results of paths in $\operatorname{OD}(1,17)$ was listed in Table 6 . From this Table, it can be seen that there are some bottlenecks in the above paths. For instance, the travel time reliability of path 31-29-27-25-52-56-17 is 0.485, of path 31-29-40-44-11-13-15-17 it is 0.497, and of path 31-29-27-25-23-21-20 it is 0.470. The results are expected because the link 31, 29, 27, 25 and 23 are the bottlenecks in the road network, less surplus capacity is available to accommodate the travel demand and traffic fluctuation. According to formula (10), the travel time reliability of $\operatorname{OD}(1,17), \operatorname{OD}(3,16), \operatorname{OD}(17,1)$, $\mathrm{OD}(16,3)$ under small snowfall conditions are 0.517 , $0.526,0.504$, and 0.528 , respectively. According to formula (14), the travel time reliability of the road network is 0.520 .

With the same method, the travel time reliability of the road network under other different conditions may be calculated. Due to space constraints, the intermediate results are omitted, the final results are shown in Table 7 . The results show that the ice and snowfall conditions have extraordinary influence on the travel time reliability of road network. For instance, the travel time reliability of $\operatorname{OD}(1,17)$ is 0.541 under normal conditions, 0.517 under little snow, 0.370 under moderate snow, 0.303 under heavy snow, and 0.319 under glare ice. Therefore, it is important to control the travel demand to improve the travel time reliability under ice and snowfall conditions in the traffic management. 
Table 6 - Travel time reliability of partial paths of $O D(1,17)$ under slight snowfall

\begin{tabular}{||c|c|c|c||}
\hline NO. & Paths & Travel cost & Travel time reliability \\
\hline \hline 1 & $2-4-5-7-9-11-13-15-17$ & 0.3011 & 0.523 \\
\hline 2 & $2-35-38-7-9-11-13-15-17$ & 0.2826 & 0.544 \\
\hline 3 & $2-35-41-47-50-15-17$ & 0.2747 & 0.551 \\
\hline 4 & $2-35-41-47-53-56-17$ & 0.2830 & 0.501 \\
\hline 5 & $31-29-27-25-52-56-17$ & 0.2801 & 0.485 \\
\hline 6 & $31-34-38-7-9-11-13-15-17$ & 0.2858 & 0.509 \\
\hline 7 & $31-29-40-44-11-13-15-17$ & 0.2984 & 0.497 \\
\hline 8 & $31-29-27-46-50-15-17$ & 0.2763 & 0.526 \\
\hline 9 & $31-29-27-25-23-21-20$ & 0.2911 & 0.470 \\
\hline 10 & $31-29-27-46-53-56-17$ & 0.2846 & 0.514 \\
\hline \hline
\end{tabular}

Table 7 - Travel time reliability of partial road network in Harbin under different conditions

\begin{tabular}{|l|c|c|c|c|c||}
\hline \multicolumn{1}{|c|}{ Conditions } & $\mathrm{OD}(1,17)$ & $\mathrm{OD}(3,16)$ & $\mathrm{OD}(17,1)$ & $\mathrm{OD}(16,3)$ & Road network \\
\hline \hline Normal & 0.541 & 0.563 & 0.530 & 0.552 & 0.549 \\
\hline Little snow & 0.517 & 0.526 & 0.504 & 0.528 & 0.520 \\
\hline Moderate snow & 0.370 & 0.383 & 0.355 & 0.371 & 0.369 \\
\hline Heavy snow & 0.303 & 0.314 & 0.290 & 0.318 & 0.308 \\
\hline Glare ice & 0.319 & 0.325 & 0.311 & 0.326 & 0.321 \\
\hline
\end{tabular}

\section{CONCLUSIONS}

1) By introducing corrective functions of free travel time and capacity under ice and snowfall conditions, ISB-BPR function was constructed, and the corrective function and BPR parameters were calibrated with field observation data. It expands the application range of the BPR function, and provides references to the study of traffic flow theory under ice and snowfall conditions.

2) According to the concept limitation of travel time reliability of road segment and intersection, the quantitative relationship between LOS and travel time reliability was studied and the new concept of travel time reliability was defined. The travel time reliability assessment models for road segment and intersection were constructed respectively.

3) By breaking through the series systematic theory, the model of path travel time reliability was constructed. By breaking through general parallel systematic theory, the OD pair travel time reliability model was established. The relationships of travel time reliability of road segment, intersection, path and OD pair were analyzed, and the evaluation model of travel time reliability for road network was constructed. A partial road network was taken as an example to validate the effectiveness and practicality of the evaluation methodology

\section{ACKNOWLEDGEMENTS}

This research was supported by China Postdoctoral Science Foundation 2011M500676, National Education Ministry Humanities and Social Sciences Foundation 12YJCZH097, Heilongjiang Institute of Technology Doctoral Science Foundation 2011BJ05 and Technology Research and Development Program of Shandong 2012G0020129.

We are also grateful to the anonymous referees for their helpful comments and constructive suggestions on an earlier version of the manuscript.

冷军强 ${ }^{1} 2^{*}$, 冯雨芹 ${ }^{3}$, 张亚平 $^{2}$, 何逸 $^{2}$

1哈尔滨工业大学 管理学院 哈尔滨 中国

2哈尔滨工业大学 汽车学院 威海 中国

3 黑龙江工程学院 汽车与交通工程学院 哈尔滨 中国

\section{冰雪条件下城市路网行程时间可靠性模型}

摘要: 为冰雪条件下城市交通规划、应急管理等提供 理论支撑, 论文研究冰雪条件下城市路网行程时间可靠 性。引入冰雪条件对路段自由行程时间及通行能力影响的 修正函数，建立冰雪条件下路段行程时间函数，利用实地 调查数据, 针对不同类别道路的修正函数进行标定。基于 现有路段、交叉口行程时间可靠性概念的局限性，提出新 的行程时间可靠性定义，结合已标定的行程时间及延误模 型建立路网单元行程时间可靠性模型。突破以串联系统理 论建立路径行程时间可靠性模型的传统思路, 将路径作为 整体对其行程时间可靠性进行研究; 突破以并联系统理论 
建立OD(Original Destination)对行程时间可靠性模型的方 法，求取各路径行程时间可靠性的加权平均值; 利用OD 对行程时间可靠性构建路网行程时间可靠性模型; 将以上 模型应用于实际路网评价，验证其有效性与实用性。 关键词：行程时间可靠性；ISB-BPR函数； 平 ; OD对

\section{LITERATURE}

[1] Asakura Y., Kashiwadani M.: Road Network Reliability Caused by Daily Fluctuation of Traffic Flow. Proceedings of the 19th PTRC Summer Annual Meeting, Brighton, 1991, pp.73 84

[2] Asakura Y.: Reliability Measures of an Origin and Destination Pair in a Deteriorated Road Network with Variable Flows. Transportation Networks: Recent Methodological Advances. Selected Proceedings of the 4th EURO Transportation Meeting, Newcastle, England 1996. Amsterdam, New York: Pergamum, 1999, pp.273 287

[3] Lida Y.: Basic Concepts Future Directions of Road Network Reliability Analysis. Journal of Advanced Transportation. 1999, 33(2), pp.125 134

[4] Lam W. H. K., Xu G.: A Traffic Flow Simulator for Network Reliability Assessment. Journal of Advanced Transportation. 1999, 33(2), pp.159 182

[5] Lam W. H. K., G. Xu.: Calibration Traffic Flow Simulator for Network Reliability Assessment. Reliability of Transportation Networks. 2000, pp.139 158

[6] Chen A., Recker W.: Considering Risk Taking Behavior in Travel Time Reliability. Transportation Research Board 80th Annual Meeting, Washington, D.C., 2000

[7] Lomax T., Tumer S., Margiotta R.: Monitoring Urban Roadways in 2000: Using Archived Operations Data for Reliability and Mobility Measurement. Texas Transportation Institute and Cambridge Systematies, Inc., 2002
[8] Chen C., Skabadonis A., Varaiya P.: Travel-time Reliability as a Measure of Service. Transportation Research Record. 2003, (1855), pp.74-79

[9] Al-Deek H., Emam E. B.: New Methodology for Estimating Reliability in Transportation Networks with Degraded Link Capacities. Journal of Intelligent Transportation Systems. 2006, 10(3), pp.117 129

[10] Tu H., Van Lint H., Van Zuylen H.: Measuring and Defining Freeway Travel Time Reliability. $5^{\text {th }}$ International Conference on Traffic and Transportation Studies, ICTTS, Xi'an, China, 2006. Reston, United States, American Society of Civil Engineers, 2006, pp.473 481

[11] Tu H., Van Lint H., Van Zuylen H.: Real Time Modelling Travel Time Reliability Using Cell Transmission Model. $5^{\text {th }}$ International Conference on Traffic and Transportation Studies, ICTTS, Xi'an, China, 2006. Reston, United States, American Society of Civil Engineers, 2006, pp.461 472

[12] Shao H., Lam W. H. K., Tam M. L., Yuan X. M.: Modelling Rain Effects on Risk-Taking Behaviours of Multi-user Classes in Road Networks with Uncertainty. Journal of Advanced Transportation. 2008, 42(3), pp.265 290

[13] Lam W. H. K., Shao H., Sumalee A.: Modeling Impacts of Adverse Weather Conditions on a Road Network with Uncertainties in Demand and Supply. Transportation Research Part B. 2008, 42(10), pp.890 910

[14] Higatani A., Kitazawa T., Tanabe J. et al.: Empirical Analysis of travel Time Reliability Measures in Hanshin Expressway Network. Journal of Intelligent Transportation Systems: Technology, Planning, and Operations, 2009, 13(1), pp.28 38

[15] Sohn K., Kim D.: Statistical Model for Forecasting Link Travel Time Variability. Journal of Transportation Engineering. 2009, 135(7), pp.440 453

[16] Leng J.Q.: Travel Time Reliability of Urban Road Network under Ice and Snowfall Conditions. Dissertation for the Doctoral Degree in Engineering, Harbin Institute of Technology. 2010, pp. 40 42 